\title{
Interdisciplinaridade na história e na psicologia: do "tribunal da impotência" à impotência como conflito interno
}

\author{
Inter-disciplinarity in history and psychology: \\ from the "courts of impotence" to impotence \\ as an internal conflict
}

\author{
Alzira Lobo de Arruda CAMPOS' \\ Joaquim Gonçalves COELHO FILHO' \\ Ligia Caran Costa CORRÊA
}

\begin{abstract}
Resumo
A psicologia entende-se perfeitamente com a história, uma vez que o presente e o passado unem-se no método científico psicanalítico. No divã do psicanalista ou no ambiente social, o presente é invadido pelo passado por intermédio do cotidiano, da literatura, da moral, do direito, da linguagem, das ciências, das técnicas, das artes. Com o objetivo de ilustrar a interdisciplinaridade na história e na psicologia, são discutidas duas visões sobre a sexualidade: a primeira refere-se à exteriorização extrema da impotência, a partir do julgamento de impotentes; a segunda seleciona a interiorização da culpa por meio da transformação de procedimentos legais de inculpação do impotente em conflitos internos. Destaca-se, assim, a visita à história, à procura de vítimas de tribunais a serviço da repressão dos incapacitados, e a visita aos porões da história de pacientes, à procura de formas para a supressão da repressão mental que os incapacitou.
\end{abstract}

Unitermos: Impotência. Interdisciplinaridade. Sexualidade.

\begin{abstract}
Psychology and history are perfect bedfellows, since the present and the past come together in the psychoanalytical scientific method. On the psychoanalyst's couch or in the social setting, the present is invaded by the past through the daily routine, literature, morals, law, language, science, technology, the arts. With the purpose of illustrating the inter-disciplinarity of history and psychology, two views of sexuality are discussed: the first refers to an extreme externalization of impotence, based on the judgment of those who are impotent; the second view selects the internalization of guilt, by means of the transformation of the legal procedures incriminating the impotent subject in internal conflicts. Thus, the visit to history stands out, in the search for victims of the courts, in the service of the repression of the disabled, and the visit to the fundaments of the patients' history in the search for ways to suppress the mental repression that disabled them.
\end{abstract}

Uniterms: Impotence. Interdisciplinarity. Sexuality.

1 Universidade São Marcos, Programa de Pós-Graduação, Mestrado Interdisciplinar em Educação, Administração e Comunicação. Av. Nazaré, 900 , 04262-100, São Paulo, SP, Brasil. Correspondência para/Correspondence to: J.G. COELHO FILHO. E-mail: <joaquim@ippesp.com.br>. 
As fronteiras das ciências, na atualidade, apresentam-se em fermentação. Os limites estritos das áreas científicas, demarcados pela universidade moderna na segunda metade do século XIX, revelam-se inadequados para resolver problemas colocados pelo universo em rede. $O$ século $X X$ tratou de interações entre áreas científicas e métodos diversos, contrapondo-se à unilinearidade contida na "ciência positiva". Essas interações são realizadas no campo da multi, inter ou transdisciplinaridade, denominações que apresentam em si próprias a exigência de "derrubar os muros" entre os campos científicos (Campos \& Mesgravis, 2006). Essas autoras destacam as concepções que se tornaram usuais quanto à pesquisa monodisciplinar, que abrange disciplina e campo de pesquisa únicos; à multidisciplinar, que trabalha em rede de disciplinas, mas não promove a integração de conceitos ou métodos de uma área científica para outra; à interdisciplinar, caracterizada por uma rede "aberta" de disciplinas, que promove as intervenções teóricas e metodológicas de uma para outra; e à transdisciplinar, que apresenta uma rede ainda mais aberta, por postular a geração de novos conceitos e métodos, ultrapassando as fronteiras disciplinares.

A "derrubada de muros" entre os campos científicos já se fazia presente nos trabalhos de Bleger (1975), quando este considerava um grande erro supor que a cada ciência particular correspondia uma área de conduta, como a psicologia para a área da mente, a biologia para a área do corpo e a sociologia para as manifestações na área do mundo externo, por exemplo. Bleger defende, ainda nesse mesmo texto, que não há acontecimentos no ser humano que sejam do domínio exclusivo de um único campo científico ou que devam ser estudados exclusivamente por uma ciência.

Nesse âmbito, a psicologia entende-se perfeitamente com a história. De fato, a começar pela psicoterapia, que se aproveita, em sua área específica de conhecimento, de técnicas utilizadas pela humanidade desde os seus primórdios, quando os homens reuniamse em torno de fogueiras para compartilhar experiências, procurando diminuir tensões individuais e coletivas. As rodas de convívio, os círculos sociais e as instituições que compõem o universo comunitário baseiam-se em trocas lingüísticas, durante as quais as pessoas esperam diminuir suas angústias, criar alianças e eliminar opo432 sitores. É nesse campo vastíssimo que se situam os boatos e as "fofocas", que fornecem alimento espiritual à humanidade. Freud converteu o valor terapêutico da palavra em um método científico consensualmente reconhecido.

Presente e passado unem-se neste ritual. No divã do psicanalista ou no ambiente social, o presente é invadido pelo passado por intermédio do cotidiano, da literatura, da moral, do direito, da linguagem, das ciências, das técnicas, das artes. Como narrativa ou modelo explicativo, a memória dos fatos que"realmente aconteceram" ajuda as sociedades do presente a se organizarem de forma mais eficaz, evitando, ao menos, que retomem caminhos equivocados. Também os indivíduos, em suas sessões de psicanálise, relembram experiências malsucedidas e organizam-se para não repeti-las.

A união entre passado e presente patenteia-se no campo da sexualidade, campo de natureza vária trilhado por especialistas que, de um modo ou de outro, aceitam a idéia muito expandida no Ocidente de que dificuldades particulares são enfrentadas no plano sexual e que elas são imputáveis à moral tradicional, de essência cristã. Idéia exorbitante, cuja aceitação tornaria legítima a suposição de que as dificuldades seriam suplantadas caso se renegasse a moral advinda dos pais e se adotasse, por exemplo, a dos Nhambiquaras, hipótese esta tão absurda quanto a de se acreditar ser possível fazer do passado uma tabula rasa. Muito mais viável seria partiIhar a posição assumida por diversos historiadores, tais como Flandrin (1981) e Darmon (1979, 1981), que defendem a ação terapêutica da História sobre a sexualidade. Em um século em que a Psicanálise suscita tanto entusiasmo, parece ilógico ouvir com tanta atenção o passado dos indivíduos submetidos à cura psicanalítica, e tampouco o seu passado coletivo.

A concepção psicanalítica trabalha com o pressuposto teórico de que os traumas passados marcam uma cultura. Todo comportamento humano - individual ou coletivo - é culturalmente modulado. Do prisma da sexualidade, a reapreciação do sistema de valores serviria para suplantar dificuldades presentes e contribuir para modificar a visão que uma cultura anacrônica dá do amor, do casamento, do comércio sexual, da relação pais-filhos, da vida sexual dos celibatários. Se há séculos o amor é o tema favorito dos poetas e dos romancistas, parece verossímil que seja também o de 
preferência de seu público, suscitando um interesse, à primeira vista, desmesurado da coletividade (Flandrin, 1981).

A esse respeito, vale a pena lembrar que a curiosidade insaciável sobre os parceiros sexuais do outro corresponde a uma necessidade social profunda. De um lado, selecionar um parceiro da mesma classe social garante o status quo, impedindo que o patrimônio familiar resvale para outras camadas da sociedade. De outro lado, a política natalista, que imperou na humanidade até o século XVIII, fazia com que o exercício da sexualidade fosse de alto interesse para o poder político, preocupado em aumentar trabalhadores e soldados em seus países. Daí ter sido a sexualidade assoberbada por regras de comportamento que condenavam seus transgressores a penas variáveis em severidade, que poderiam chegar à pena capital, em casos considerados mais graves. A inculcação de modalidades sexuais prescritas operava-se por meio de sermões contra a luxúria e o pecado, que mereceram as maiores atenções dos sermonistas, preocupados em traçar limites claros entre o sexo legítimo (destinado à procriação) e o ilegítimo (tendo o prazer por objetivo). A sexualidade formava-se sob a dialética de "culpa e castigo", estigmatizando ritualmente homens e mulheres desviantes. Para transgressões consideradas mais graves, os réprobos poderiam ser levados à barra dos tribunais, e sobre eles recaía a condenação geral.

A clareza sobre o assunto tinha evidente valor pedagógico. As regras eram explícitas e feitas para desencorajar comportamentos transgressivos. Entretanto, a declaração dos direitos do homem e do cidadão, a marcha do feminismo e numerosas conquistas científicas no campo biológico puseram abaixo a moralidade tradicional e discriminaram o sexo. Não obstante, a sexualidade, hoje liberta de cadeias formais, estaria isenta de estigmas que lhe foram impostos pelo passado?

A fim de contribuir para elucidar a questão acima, escolheu-se como objeto de análise para este artigo o tema da impotência, de enorme interesse social e que se encontra, paradoxalmente, localizado em uma das zonas de silêncio cultural. O homem, prisioneiro do mito da virilidade, esconde os seus fracassos utilizando-se de manobras diversionistas, como a exuberância que exibe em falar sobre a impotência alheia.
Neste terreno e para os fins deste artigo, procuram-se visões sociais sobre a sexualidade, no passado e no presente. Do passado, retém-se a exteriorização extrema da impotência, pela análise do julgamento de impotentes com base na obra de Darmon (1979), Le tribunal de l'impuissance, virilité et défaillances conjugales dans l'Ancienne France. Do presente, seleciona-se a interiorização da culpa pelo impotente, operada pela substituição dos procedimentos legais de inculpação por conflitos internos, que abrem mão de instrumentos penais exteriores por não serem estes mais necessários.

\section{A interdisciplinaridade em Pierre Darmon}

Pierre Darmon nasceu em Oran, em 1939. Fez-se conhecer pelo Mito da procriação na idade barroca, publicado em 1977. Em 1979, publicou O tribunal da impotência - virilidade e fracassos conjugais na Antiga França, oriundo de uma tese que sustentou, sob a orientação de Robert Mandrou, sobre os Processos de nulidade do casamento por impotência - em França principalmente, do XVI ao XVIII século - e sua herança contemporânea. O Tribunal da impotência continua as indagações de Darmon sobre os sistemas de geração, de Hipócrates a Harvey e, especialmente, os instrumentos da procriação, com o "prestígio e esplendor da verga". Desse prestígio e esplendor, Darmon extrai a degradação social, jurídica e médico-legal dos homens impotentes, trazendo sua reflexão para a longa duração de estruturas mentais e as conjunturas cronologicamente definidas por momentos históricos que ele analisa em profundidade.

Em O tribunal da impotência, Pierre Darmon entende que a exaltação da virilidade e a condenação do impotente representariam, além de uma reação de compensação, uma realidade mais grave ligada à explosão discursiva sobre o sexo, operada no final do século XVI, quando a sexualidade encontrou efetivamente uma compensação no extravasamento verbal, rico em tendências obsessivas, uma vez que os relatos de alcova passaram a apresentar minúcias e pormenores até então banidos socialmente. Ao lado de uma política sexual natalista, destinada a prover os quadros da produção e do exército e levada a efeito pelos estados nacionais, desenvolveram-se processos repressivos ligados à domesticação dos corpos, necessária para garantir o 
poder de um Estado concebido como de direito divino. A ordem social, de outro lado, viu-se ameaçada pelas "classes perigosas", ameaça tornada mais temível pela explosão demográfica do século XVIII. Como controlar uma população que crescia em seus porões sociais, ameaçando a sustentação dos andares superiores?

Como ocorre em obras congêneres, a interdisciplinaridade apresenta-se inspirada em Michel Foucault, o pensador da descontinuidade e do mutacionismo, que privilegia as rupturas bruscas e a emergência de estruturas novas, no quadro quase imóvel da longa duração. Assim como em Foucault, os trabalhos de Darmon fazem aflorar estruturas de natureza vária (rigidez do sistema social, rotina mental etc.), ao implicar, ao mesmo tempo, a delimitação de um espaço de análise, a determinação das cesuras cronológicas significativas e a distinção das temporalidades próprias das diversas instâncias do real. Ambos os autores põem em causa os cortes habituais entre as disciplinas (filosofia, direito, psicologia, literatura, história etc.), porque uma idéia remete a outra, inscrevendo-se em um campo de discursos associados e assentando-se amplamente no já dito. Neste terreno, é preciso renunciar a atribuir valores desiguais aos enunciados de diferentes textos, apegando-se às regras que condicionam a produção dos discursos em uma época dada.

Na"economia do corpo"e em sua domesticação, Foucault e Darmon atacam o racionalismo burguês, procurando, por detrás dos atos, as regras de um fazer e, sob os enunciados, a gramática que os comanda (Bourdé \&Martin, 1983).

Em sua história da sexualidade, Foucault (1977) discute a "vontade de saber" da sociedade sobre a vida sexual do indivíduo - em princípio aquilo que ele tem de mais íntimo. Esta perquirição pode ser acompanhada no pensamento de Darmon (1981), como se pode ver em Le mythe de la procréation à l' âge baroque, que não se propõe a retraçar a verdade em matéria de procriação, mas estudar os preconceitos, superstições e tabus que dificultaram o progresso da embriologia. Nesta obra, Darmon (1981) analisa a revolução ovista e animalculista, que não conseguiu dissipar todos os preconceitos e que, paradoxalmente, não conseguiu sensibilizar os sábios - estes, pertinazes, ocuparam-se com conside434 rações que os distanciavam cada vez mais da verdade.
Por um fenômeno que nada tem de surpreendente, estes sábios permaneceram fora do espírito do tempo. Imperturbável, a Faculdade de Medicina passou pelas revoluções ovista e animalculista e continuou a submeter a seus estudantes temas de teses que se inscrevem em linha direta com a tradição do período da Antiguidade. A procriação não se vê, ela é imaginada, e continua sendo o domínio de visionários românticos e místicos. Observa Darmon (1981) que sonho e poesia aí se confundem em uma espécie de festa barroca, da qual emana uma beleza estranha e fascinante:"quando se descobre, para o fim do século XIX, que todo ser provém da fusão dos núcleos respectivos de duas células, macha e fêmea, prelúdio de um fenômeno grandioso de multiplicação e de diversificação celular, a geração, perdendo um pouco de seu mistério, perde também muito de seu encanto" (p.6).

Darmon constrói um modelo de análise que une estreitamente a História à Antropologia, à MedicinaLegal, ao Direito, à Psicologia e à Literatura. A primeira, pela cultura, consubstanciada em comportamentos, crenças, superstições e tabus; a segunda, como ciência repositória da verdade sobre a sexualidade prescrita e proscrita pela sociedade; a terceira, como detentora da verdade jurídica sobre o assunto; a quarta comparece fartamente, nos complexos individuais e coletivos, na análise das personagens e fatos históricos, à luz da documentação; a quinta é visualizada por escolhas estilísticas, que aproximam a obra acadêmica ao livro destinado a um público não especializado, pela renúncia a ranços acadêmicos e por uma linguagem irreverente e bem-humorada. Ademais, o autor utiliza-se largamente de fontes literárias, da narrativa descritiva e de diálogos retirados da documentação - estes últimos, de alguma forma ficcionados pela presentificação de razões e contra-razões nas pessoas das partes contrárias.

O problema da investigação justifica a interdisciplinaridade. O livro analisa o "drama estranho e desconhecido" de todos aqueles que, em razão de uma sexualidade reputada como falha, viram-se levados perante o juiz para pagar "o resgate do mito ancestral da virilidade". Mas o livro retrata também a história de todos aqueles que, em nome de um atributo viril que funciona segundo as normas do direito canônico, se erigem em juízes e pesquisadores zelosos do impotente (Darmon, 1979). 
Darmon divide suas reflexões em três partes, delimitadas disciplinarmente:

1. Mariage et Impuissance apresenta a visão histórica da Igreja sobre o tema e discute as razões complexas que levaram a patrologia romana a misturar, em mesmo cadinho, o sacramento do matrimônio e a obscenidade de procedimentos investigatórios da impotência assacada a homens e mulheres, vítimas passíveis de serem reduzidas à categoria de sacrílegas;

2. Les procédures juridiques de nullité du mariage analisa o quadro geral dos processos de impotência, contendo procedimentos preliminares e interrogatório;

3. Les procédures médico-legales jusqu'au XVIII siècle reflete sobre o poder médico, explicitado desde a determinação da perícia dos órgãos genitais e o comportamento da equipe técnico-científica indicada para a perícia, até a prova espantosa do "congresso", um ritual de "pornografia sagrada" durante o qual o casal litigante deveria se unir em cópula diante de um público juridicamente ordenado. Parteiras, cirurgiões e médicos obedecem a um formalismo jurídico, cujo ritmo instável, ritual imperturbável e frieza escondem as paixões mais intensas e impuras. A superioridade insolente dos médicos sobre os cirurgiões conduz a uma valorização excessiva da perfeição médica, em detrimento de uma cirurgia reduzida ao nível de "salsicharia". As perícias representam uma lição de anatomia, com funções definidas pelo status profissional diferenciado de seus protagonistas: os cirurgiões apal pam, trituram, dissecam, enquanto os médicos raciocinam, dissertam, conjecturam. Sobre o laudo produzido, resultado de meras especulações de espírito, repousa a sentença final do juiz da Igreja. Na verdade, o processo sobre a impotência fornece aos médicos e, na esteira destes, aos cirurgiões e às próprias matronas, uma oportunidade de afirmar seu poder (Darmon, 1979). A visita feminina é descrita pelo jurista Anne Robert com um realismo chocante e de uma audácia inaudita, que exerce atração irresistível sobre o público, "uma espécie de fascinação traumatizante e durável"sobre a qual pergunta Darmon:"como ficar insensível ao sabor desse velho francês tão nobremente apimentado de jocosidade rabelaisiana?". Segue a jocosidade do jurista:

Desejais que esse espetáculo seja representado em palavras? Perdoem-me castas orelhas, se em algo vergonhoso minhas palavras expressam um não sei quê de pouco casto e vergonhoso. Faz-se deitar uma jovem em todo seu comprimento, estendida sobre as costas, as coxas escanchadas, uma cá, outra lá: vê-se claramente as partes pudendas, às quais a natureza quis ocultar para o prazer e a alegria dos homens. As matronas, que são parteiras e velhas, e os médicos as observam atentamente, as manuseiam e as abrem. O juiz, que está lá presente, faz boa cara, e se segura para não rir. As matronas que assistem se recordam de seus antigos ardores, que estão há muito tempo esfriados. Os médicos, segundo sua idade, recordamse de suas primeiras forças. Os outros, fazendo os impedimentos, alimentam-se de um vão e inútil espetáculo. O cirurgião, ou empunhando um instrumento feito especialmente, que eles chamam de espelho do útero, ou com um membro viril feito de cera, ou de outro material, sonda o vau da entrada do antro venéreo, faz a abertura, dilata, estende e alarga os lugares. A moça deitada com o corpo todo estendido sente a parte que Ihe dá comichão; de tal modo que agora ela se quer fazer visitar estando virgem; todavia, ela não sai de lá sem que esteja corrompida e desgastada. É vergonha dizer mais sobre isso (Robert, 1622, p.209).

Uma misoginia indisfarçável apresenta-se em todo o processo, mesmo na pena dos advogados das mulheres que acusam seus maridos de impotentes.

Não se pode perder de vista que uma visita masculina implicava a perícia dos órgãos genitais e de seu funcionamento, isto é, a prova da ereção ("erguer, entrar, molhar"). Portanto, o crime de Onã, personagem bíblico que se negava a dar descendência a seu irmão morto, a despeito das recomendações de seu pai, Judá, é então erigido em instituição canônica, visto que, toda vez que Onã se unia à mulher de seu irmão, derramava o sêmen no chão para não lhe dar descendência.

Um"epílogo"substitui a conclusão. Nele, Darmon discute a longa duração do julgamento do impotente, situando-o nos dias atuais.

Darmon não cita autores contemporâneos, com exceção de Foucault. Trata-se de trabalho baseado apenas em fontes: das eclesiásticas às literárias, jurídicas, médico-legais, históricas, bem como as memórias.

No Brasil, o mito da virilidade, com a condenaação daqueles que a ele não correspondam, torna-se mais agudo pelo machismo latino e pela herança dada pela escravidão. Infelizmente, as fontes são mais precárias 
do que as européias. A começar pelo assunto que se encontra escamoteado pelas fontes, substituindo o marido impotente pelo cristão que pretende seguir o exemplo de José e Maria.

\section{A interdisciplinaridade em Sigmund Freud}

O mesmo período focalizado por Darmon, agora sob as lentes de Sade, o Marquês, foi retratado como aquele em que o obsceno passou a ser dito publicamente, e não somente no calor das alcovas ou na expiação religiosa, em situações de confissão. Sade, fruto da repressão de antanho, propõe a verbalização do abominável, em busca da violação da natureza humana. Instala-se a discussão sobre a verdadeira natureza do homem (Loparic, 1999). A era dos libertinos franceses confronta-se com os valores éticos e morais de seu tempo. Um grito de revolta fica parado no ar. Nas palavras de Peixoto (1979, p.11),

Um grito desesperado e angustiado, o incontrolável extremo de um individualismo absoluto que limita bastante o alcance ou o significado de suas idéias, a ânsia de liberação, gigantesco protesto em favor do homem livre, a denúncia de uma civilização fundamentada nos instintos planejadamente reprimidos, baseada na hipocrisia, no preconceito, na corrupção, na injustiça, na divisão social e na mais feroz crueldade.

Os iluministas, em socorro à aristocracia em declínio, arrebataram para si a tarefa de regulamentar o dizível, na tentativa de recolher o grito parado no ar. Para eles, a verdade dita estava acima do bem-estar comum. A palavra, em liberdade condicional, tinha tempo e hora para ser discursada. A linguagem, então, refletia o possível e não mais o desejável.

Pouco mais de um século à frente, encontra-se Freud às voltas com a fala do abominável, revestindo-a de caráter científico, ao propor a cura pela fala (talking cure), em que o sintoma é interpretado a fim de que passe a fazer sentido para o paciente em situação clínica, em busca da dissolução do sintoma. Mais uma vez, estudiosos de natureza vária debruçam-se sobre o abominável - não mais explícito, não mais carnal. A interdisciplinaridade se faz presente. São olhares multiformes sobre o obsceno, que insiste em não se apresentar para a consciência, mas que se manifesta na ação.
Mais do que uma avaliação isolada como a relatada por Darmon acerca do tribunal da impotência, o projeto freudiano prima por aprofundar os estudos sobre a linguagem e o princípio da constância. A constância do reprimido apresenta-se na ação versus a insistência da interpretação da ação, na tentativa de transformá-la em palavra.

Embora Freud refletisse a tradição da anatomia patológica alemã, inspirada no olhar da nova clínica sugerida por Foucault, que estudava as patologias utilizando-se de técnicas anatômicas (Gabbi Jr., 1994), ele rompeu com essa tradição e passou a perseguir o invisível. Aqui reside o fato de Freud ser tido como um dos grandes pensadores do século XX. Ao romper os limites apresentados por Breuer no tratamento da mais famosa paciente da nova ciência, Anna O., Freud abandonou os estudos de enfoque anatômico, passando a dedicar-se às investigações e ao estudo da etiologia das neuroses, reflexos da formação dos sintomas histéricos, da repressão do dizível e da afasia assimbólica - esta última associada à dicotomia entre representação de palavra e de objeto, da qual decorre a prática da psicoterapia clássica em procurar restaurar a associação da palavra com o estado afetivo e libertar a palavra dos grilhões da censura. Este é o cerne do problema psicológico do projeto freudiano. Trata-se de um novo tribunal: o tribunal da censura, do recalcado, do conflito interno.

Freud lança-se em estabelecer uma relação mais estreita entre a cultura da moralidade e a dinâmica psicológica do recalcamento. Em 1897, com a entrada em cena de Édipo e Hamlet, Freud consegue alargar os limites do conceito da cultura da moralidade, localizando os fantasmas dos mitos nos arredores das cenas originais. Acha-se diante das angústias derivadas dos desejos; da repugnância provocada por eles; da rejeição dos desejos como defesa do impensável e do indizível. A impotência não é mais somente física; é uma impotência observada também no plano psicológico, diante dos mitos endopsíquicos, diante de um saber "sabido", embora não-consciente.

A despeito do axioma de que a história nada é sem a cronologia, sobressaem os equívocos que a noção de cronologia suscita - por exemplo, diante da sedimentação dos processos de cultura. Freud, fugindo aos equívocos da cronologia, identifica o exercício da 
transferência, em que os sentimentos do passado são atualizados nas novas relações estabelecidas. Fala-se do sentimento de impotência atualizado e não mais da impotência física. Existe um método psicanalítico. A noção de transferência outorga-lhe seu estatuto.

A noção de transferência já se fazia presente, desde 1895, nos estudos de Freud sobre a histeria. Em contato com sua paciente Elisabeth Von R., no final do ano de 1892, e diante da impotência vivenciada por ela em função da morte do pai e da cirurgia realizada no olho da mãe, seguida da morte da irmã casada (decorrente de afecção cardíaca após o puerpério), Freud encontrou uma jovem de 24 anos que andava curvada para frente. Sua marcha não denotava nenhum tipo patológico reconhecido, e sua queixa resumia-se à grande dor ao andar e ao cansaço ao caminhar e ficar em pé. Para Freud, a dor não tinha um caráter definido, o que o levara a crer em algo da natureza de uma fadiga dolorosa, conforme suas próprias palavras:

Uma área bastante grande e mal definida da superfície anterior da coxa direita era indicada como foco das dores, a partir da qual elas se irradiavam com mais freqüência e onde atingiam sua maior intensidade. Nessa região, a pele e os músculos eram também particularmente sensíveis à pressão e aos beliscões (embora uma picada de agulha provocasse, quando muito, certa dose de indiferença). A hiperalgia da pele e dos músculos não se restringia a essa região, mas podia ser observada mais ou menos em toda extensão das duas pernas. Os músculos eram talvez mais sensíveis à dor do que a pele; mas não havia dúvida de que as coxas eram as partes mais sensíveis a essas duas espécies de dor. A força motora das pernas não podia ser qualificada de pequena e os reflexos eram de intensidade média. Não havia outros sintomas, de modo que não existia fundamento para se suspeitar da presença de qualquer afecção orgânica grave. O distúrbio se desenvolvera gradativamente durante os dois anos anteriores e variava bastante em intensidade (Freud, 1893/1995, p.161).

Freud confessa não ter sido fácil chegar a um diagnóstico, mas recorre a uma descrição que o ajudou a refinar sua opinião, reconhecendo que ao estimular a região sensível à dor, o rosto da paciente não assumia a expressão de mal-estar ou de dor física, mas, ao contrário, seu rosto assumia uma expressão peculiar de prazer. Aqui, o tribunal coloca-se além do corpo, além da alma: fala-se do tribunal do fantasma do desejo, relativo às condições transferenciais do recalcado. Elisabeth Von R., ainda solteira e impressionada com a atenção que o seu segundo cunhado dedicava à família, foi traída por um pensamento, diante da morte da irmã, que o seu caráter moral não perdoou: "Agora ele está livre novamente e posso ser sua esposa". Este pensamento teve que ser recalcado, potencializando dores que sentia por ter dedicado tanto tempo ao cuidado de enfermos aos pés de suas camas. A conversão de pensamentos pecaminosos em dores cada vez mais localizadas representava a atualização de seus desejos, por meio de uma manifestação mais aceitável para os padrões morais.

Após muitas sessões psicoterápicas, com várias aproximações com o tema do afeto da moça pelo seu cunhado viúvo, Freud (1893/1995, p.180) pôde resgatar a representação recalcada ao expor a situação subjacente às dores, com as palavras: "Quer dizer que, durante muito tempo, você esteve apaixonada por seu cunhado". Somente após muito choro nos encontros seguintes e depois de se convencer com a explicação de Freud de que não se é responsável pelos sentimentos, e que o fato de ter adoecido comprovava o seu caráter moral, é que Elisabeth pôde começar a retomar a sua vida, agora sem a necessidade de se defender de seus pensamentos.

Pela primeira vez, Freud confessou que a atividade da psicoterapia causava-lhe estranheza, uma vez que, assim como outros neuropatologistas, sempre empregara diagnósticos locais e eletroprognósticos, mas que, diante da natureza daquele caso, consolavase com a certeza de que os procedimentos anteriormente adotados não o levariam a nada. Termina sua reflexão reconhecendo que "Os casos clínicos dessa natureza devem ser julgados como psiquiátricos; entretanto, possuem uma vantagem sobre estes últimos, a saber, uma ligação íntima entre a história dos sofrimentos do paciente e os sintomas de sua doença - uma ligação pela qual ainda procuramos em vão nas biografias das outras psicoses" (Freud, 1893/1995, p.184).

Embora falasse da história dos sofrimentos do paciente, Freud nunca perdeu de vista a influência da cultura na determinação do proibido, do indizível. Para ele, o recalcamento seria o retorno ao estado instintivo que, pela definição da cultura, seria a referência à natureza, com seu potencial para a caracterização do 
saber "sabido" que, em última instância, constituiria o núcleo do inconsciente, um tipo de atividade mental primitiva que, posteriormente, é recoberta pela razão humana. Se, em um primeiro momento, o ser humano reflete seu patrimônio instintivo, em um segundo, refletirá a cultura, por meio da socialização das carências, dos riscos e dos conflitos decorrentes de seu enfrentamento à natureza.

\section{A história e a psicologia}

No mesmo ano em que Freud morria, nascia Darmon, que, em torno de seus 40 anos, dedicou-se ao estudo dos fracassos conjugais da França Antiga. Destacou fracassos nitidamente decorrentes de supostas falhas no funcionamento dos aparelhos reprodutores, masculino e feminino, já que era essa a função cultural atribuída aos cônjuges. Na França Antiga, o prazer, obtido na companhia de garçonnières, era impensável e indizível na configuração familiar. Somente no final do século XIX, o prazer, ou melhor, a falta dele, passou a freqüentar o âmbito familiar e a ser acolhido pela ciência, não na sua forma positiva, mas pelas conseqüências decorrentes do prazer recalcado. Nas palavras de Campos (2003), referindo-se ao período colonial do Brasil, encontram-se motivos anteriores à expressividade do prazer, que justificavam o desajuste familiar:

O débito conjugal circunscrevia-se às razões legítimas para as relações sexuais. Um dever dos esposos, que provocaria problemas no caso de um deles furtar-se a cumpri-lo. A teologia moral defrontava-se aí com um dilema. De um lado teria que considerar a postura tridentina, que privilegiava o estado da castidade e o exemplo dado por São José e Maria Santíssima. De outro, a oposição que os casais castos fariam aos fins precípuos do próprio matrimônio, isto é, a geração da prole. A tendência dominante estava em considerar inválidos os consórcios 'brancos', em razão de ser a condição oposta ao bonum prolis (p.365).

Enquanto Darmon visita a História à procura de vítimas de tribunais a serviço da repressão dos incapacitados, Freud visita os porões da história de seus pacientes à procura de formas para a supressão da repressão mental que os incapacitou. A cura psicoterápica apresenta-se, assim, como a possibilidade de renomeações do passado individual, até então vitimado por pressões do passado coletivo.

\section{Referências}

Bleger, J. (1975). Psicología de la conducta. Buenos Aires: Paidós.

Bourdé, G., \& Martin, H. (1983). As escolas históricas. (Col. Fórum da História). Portugal: Publicações Europa-América.

Campos, A. L. A. (2003). Casamento e família em São Paulo colonial: caminhos e descaminhos. São Paulo: Paz e Terra.

Campos, A. L. A., \& Mesgravis, L. (2006). Da dúvida cartesiana ao diálogo metódico: o declínio da unidisciplinaridade como via metodológica única. Tempo \& Memória: Revista Semestral do Programa Interdisciplinar em Educação, Administração e Comunicação, 4 (5), 63-70.

Darmon, P. (1979). Le tribunal de l'impuissance, virilité et défaillances conjugales dans l'Ancienne France. Paris, Éd. Du Seuil.

Darmon, P. (1981). Le mythe de la procréation à l'âge baroque. Paris: Éd. Du Seuil.

Flandrin, J-L. (1981). Sesexeet I'Occident. Évolution des attitudes et des comportements. Paris: Éd. Du Seuil.

Foucault, M. (1977). História da sexualidade I. A vontade de saber. Rio de Janeiro: Graal.

Freud, S. (1995). Sobre o mecanismo psíquico dos fenômenos histéricos: comunicação preliminar. Edição standard brasileira das obras psicológicas completas de Sigmund Freud (Vol. 2, 3a. ed). Rio de Janeiro: Imago. (Originalmente publicado em 1893).

Gabbi Jr, O. F. (1994). Freud:racionalidade, sentido ereferência. Campinas: Unicamp.

Loparic, Z. (1999). É dizível o inconsciente? Natureza Humana: Revista Internacional de Filosofia e Práticas Psicoterápicas, 1 (2), 323-385.

Peixoto, F. (1979). Sade: vida e obra. Rio de Janeiro: Paz e Terra.

Robert, A. (1622). Quatre livres des arrests et chosejugées parla cour (pp.559-560). Paris: Byllaine.

Recebido em: 2/5/2006

Versão final reapresentada em: 1/10/2007

Aprovado em: 13/12/2007 